\title{
Oral health and caries/gingivitis-associated factors of adolescents aged 12-15 in Shandong province, China: a cross-sectional Oral Health Survey
}

\author{
Meng Zhang, Jing Lan, Tiantian Zhang, Wenshuang Sun, Panpan Liu and Zhifeng Wang*
}

\begin{abstract}
Background: We aimed to analyse the oral health status of adolescents in Shandong province, including dental caries and gingivitis, and their associated factors.

Methods: Adolescents aged 12-15-years in Shandong province were recruited. Caries and gingival status were assessed following the World Health Organisation diagnostic criteria. Information including the sociodemographic, oral hygiene knowledge, attitudes and practices were collected through the questionnaire. Chi-square test and multivariate logistic regression analysis were used to investigate the oral diseases associated factors.

Results: In total, 3868 students (50.2\% males) were enrolled. Of these, 39.9\% of the participants experienced caries, and $81.7 \%$ and $31.3 \%$ had calculus and bleeding gingival, respectively. Multivariate logistic regression analysis revealed that there was an association between dental caries and toothaches, dental visits and sleeping troubles caused by oral problems $(P<0.024)$. A low-frequency of brushing, high sugar consumption and no flossing were more associated with calculus formation and gingival bleeding $(P<0.008)$.

Conclusion: Compared to caries, worse gingival condition was more prevalent among adolescents in Shandong province. Brushing behaviour is associated with gingivitis, while dental visits and toothaches are associated with caries. Hence, prevention-oriented dental visits and oral hygiene training are strongly recommended to improve oral health status.
\end{abstract}

Keywords: Dental caries, Gingivitis, Adolescents, Oral health, Associated factors

\section{Background}

Dental caries and gingivitis are the most prevalent oral diseases and bring a huge economic burden $[1,2]$. The adolescents aged $12-15$ are in the early stages of permanent dentition. Data shows that $38.5-44.4 \%$ of

\footnotetext{
*Correspondence: kqwzf@sdu.edu.cn

Department of Pediatricss Dentistry, School and Hospital of Stomatology, Cheeloo College of Medicine, Shandong University and Shandong Provincial Key Laboratory of Oral Tissue Regeneration and Shandong Engineering Laboratory for Dental Materials and Oral Tissue Regeneration, No.44-1 Wenhua Road West, Jinan 250012, Shandong, China
}

adolescents in China have dental caries [3], while 61\% and $67.3 \%$ of adolescents have gingival bleeding and calculus respectively [4]. This unfavorable oral condition would make some negative effects on the lifespan of permanent dentition. Hence, it is really important to develop good oral hygiene behaviours and lifestyle habits to improve oral health condition during this period [5]. In other words, understanding and controlling the oral diseases associated factors during this period would help adolescents better maintain their oral health. 
Compared to early childhood caries, limited data are available on the assessment of oral health status in the adolescents aged 12-15. Importantly, the oral habits and ideology formed by adolescents are related to their current and future oral health $[6,7]$. Poor oral hygiene is closely associated with dental caries and gingival inflammation [8]. At the early stage of permanent dentition, if the associated factors are not evaluated, and the intervention measures are not implemented in time to correct poor habits $[9,10]$, these irreversible oral problems will affect the life of the teeth and even the person's general quality of life [11-13]. Hence, some studies have started to pay more attention on the association of age, sex, region, socioeconomic conditions, personal and professional dental care, oral hygiene behaviours, and dental anxiety with dental caries, gingivitis and oral health-related quality of life in adolescents $[11,12,14$, 15]. These studies provided evidence and reference for designing oral health prevention strategies [16].

However, no data is available for the adolescents in Shandong province. Shandong, as one of the birthplaces of the ancient Chinese civilisation, has nearly 100 million inhabitants, and they have a special dietary habit (the major staple food is flour). Hence, this study aimed (1) to describe the prevalence of dental caries and gingivitis in 12-15-year-old adolescents in Shandong province and (2) to identify the oral diseases associated factors to provide reference for the improvement of oral health education.

\section{Methods}

This cross-sectional study uses a part of the 4th National Oral Health Survey conducted in China. All parents gave their informed consent for inclusion before their children participated in the study. The study was conducted in accordance with the Declaration of Helsinki, and the protocol was approved by the Ethics Committee of the Chinese Stomatological Association (No. 2014-003).

The sample size was calculated based on the data of the 3rd National Oral Health Survey in 2005, in which the prevalence of dental caries for those aged 12 years was $28.9 \%$. The design effect ( $\mathrm{deff}=4.5)$, significance level $(\alpha=5 \%)$, margin of error $(\delta=10 \%)$ and non-response rate $(20 \%)$ were also included in the following formula:

$$
n=\operatorname{deff} \frac{u_{\alpha} / 2^{2}}{\delta^{2}} p(1-p) .
$$

In total, 28,365 12-15-year-old adolescents should be recruited in 31 provinces across the country [17]. Hence, at least 3660 individuals should be enrolled in this study. A multistage cluster sampling method was adopted to select the sample population. The probability proportion to size sampling determined that two urban and two rural samples should be used. Cluster and quota sampling determined the three primary high schools in each region. Three hundred and twenty students ( 80 for each age group) from each school were included [18].

After giving their informed consent, the students completed the questionnaire survey and underwent an oral examination. The questionnaire collected information on the students' personal and family demographics, including age, gender, region (including Huancui, Hedong, Shouguang, Pingyi), father/mother's education level, whether they were an only child or had siblings, and the following:

(1) Oral hygiene knowledge, including the impact of brushing, bacteria, sugar, fluoride, pit and fissure sealing, and other factors that affect the teeth and gingiva.

(2) Oral hygiene attitude, mainly to evaluate whether they believe that oral health is important.

(3) Oral hygiene behaviours, including brushing habits, frequency of snacking, smoking, dentist visits, and trauma.

(4) Troubles caused by oral problems, including eating, talking, brushing, working, schooling, sleeping, smiling, easily troubled, and communicating.

Please refer to the reference [3] for detail information about the questionnaire.

Three questionnaire interviewers who underwent the screening, training and certification by the nation were arranged to collect the above information as efficiently and unbiasedly as possible. The coincidence rate of the questionnaire answers between each interviewers and trainer must exceed 95\%. The questionnaires were completed independently by students in the classroom. During this process, one staff was arranged to explain each question publicly to all adolescents in the same classroom to guild them give as the most reliable answers as possible. Parallelly, two other staffs were arranged to clarify personal doubts. At last, each questionnaire would be rechecked by corresponding staff to avoid omissions and vacancies. All procedures were carefully conducted to minimize potential bias.

All clinical examinations were implemented at schools with external equipment (portable dental chair, disposable dental mirror, ball-ended community periodontal index probe, and intraoral light-emitting diode light) [18]. The following indices were applied according to the criteria recommended by the World Health Organisation [19]. The dental caries (DMFT), calculus (CI) and gingival bleeding (GB) indexes assessed decay, missing teeth caused by decay, filled teeth and the gingival health status. All teeth present were gently probed with a CPI 
probe at six sites, including mesial, mid, and distal on both buccal and lingual surfaces. Dental caries, calculus and gingival bleeding were scored as present (1, DMFT/ $\mathrm{CI} / \mathrm{GB}>1)$ or absent $(0, \mathrm{DMFT} / \mathrm{CI} / \mathrm{GB}=0)$ and the number of teeth with DMFT, calculus and gingival bleeding were recorded. All oral examinations were performed by three certified examiners who selected from clinical dentists and trained by the nation, and were recorded by trained dental personnel. The clinical practice training for DMFT would be terminated when the Kappa value was greater than 0.8 to ensure the consistency of the interand intra-examiners (0.8-0.83 for three examiners).

Data were entered and statistically analysed using IBM SPSS Statistics version 21.0. The percentage of dental caries (DMFT), calculus and gingival bleeding were calculated and statistical analysis. The indicators were all binary variables, and the other independent variables were also categorical. All the variables were independent of each other. Hence, Chi-square, Fisher's exact and $z$ tests for post hoc comparisons, univariable logistic analysis were conducted to explore the relationship between these oral indicators and the sociodemographic and questionnaire variables. To evaluate the caries and gingivitis associated factors in adolescents, a multivariate logistic regression model (method: backward logistic regression) was used. Those variables with $P \leq 0.10$ obtained through bivariate analysis were included in the final models. A $P$ value of $<0.05$ was considered statistically significant.

\section{Results}

A total of 3868 students aged 12-15 years were enrolled. The mean age of the participants was $13.95 \pm 1.11$ and $50.2 \%$ were males. As shown in Table 1, 39.9\% of participants experienced dental caries $(87.7 \%$ DT, $0.8 \% \mathrm{MT}$, $21.5 \% \mathrm{FT}$ ), and $81.7 \%$ and $31.3 \%$ of participants had calculus and bleeding gingival, respectively. The mean (SD) value of DT, FT, DMFT, CI, and GB were $0.68 \pm 1.22$, $0.18 \pm 0.77, \quad 0.86 \pm 1.47,5.61 \pm 4.91$, and $1.58 \pm 3.58$, respectively (data not shown).

Table 1 summarises the sociodemographic variables associated with DMFT, CI, and GB. As for dental caries, there was a statistically significative association between caries and age $(P=0.041)$, gender $(P<0.001)$, living region $(P<0.001)$, with or without siblings and mother's education levels $(P=0.01$ and 0.005$)$. There was no association with urban/rural region and father's education level. As for dental calculus, age $(P<0.001)$, gender $(P<0.001)$ and living region $(P=0.032$ and 0.001$)$ were significantly associated with dental calculus, while with and without siblings and parent education level were not associated. As for gingivitis, there was a significative association between bleeding and age $(P=0.01)$, living region $(\mathrm{P}<0.001)$. However, gender, with or without siblings and parents' education levels were not associated with bleeding.

The independent behavioural variables with significant differences associated with DMFT, CI and GB, are summarised in Additional file 1: Tables S1-3. Dental caries was associated with the following variables: teeth brushing habits and brushing over two times per day (Q4 and $\mathrm{Q} 5 ; P=0.001$ and 0.035$)$, higher frequency of sugar consumption (Q9; $P<0.042)$, poorer self-evaluation of oral condition $(\mathrm{Q} 12 ; P<0.001)$, toothaches and dentist visits (Q15-18; $P<0.001)$. Furthermore, those students who did not believe that regular oral examinations are necessary $(\mathrm{Q} 20 \mathrm{~b} ; P=0.005)$ and who thought that caries had a negative impact on eating, schooling, sleeping and easily troubled $(\mathrm{Q} 21 ; P<0.002)$ were associated with a higher prevalence of dental caries. Those with a higher frequency of brushing (Q5; $P<0.001)$, higher sugar consumption (Q9a; $P=0.03)$, dental visits $(\mathrm{Q} 16 ; P=0.003)$, and believed that regular oral examinations are necessary (Q20b; $P=0.016$ ) were associated with a lower prevalence of dental calculus. In addition, a high prevalence of GB was associated with a lower frequency of brushing and flossing ( $\mathrm{Q} 5$ and $\mathrm{Q} 8 ; P=0.003$ and 0.009$)$, poorer self-evaluation of oral condition (Q12; $P=0.048)$, and the belief that gingival bleeding is normal when brushing $(\mathrm{Q} 19 \mathrm{a} ; P<0.019)$. The univariable logistic regression analysis showed similar results (see Additional file 1: Tables S4-6).

The multivariate logistic regression analysis revealed that adolescents who were older, female, living in an urban environment, had siblings, a poorer self-evaluation of oral condition, experienced toothaches, visited a dentist, and had sleeping disturbance caused by oral problems had a statistically higher prevalence of DMFT (Table 2). Interestingly, no brushing and sugar consumption variables were included in the final DMFT model. In the CI model (Table 3), there was a higher prevalence of dental calculus in those that were older, male, living in Huancui and Pingyi, and did not visit a dentist. Besides, a low-frequency of brushing (1/day: OR: 1.421, 95\% CI $1.158-1.742, P=0.001 ;<1 /$ day: OR: $1.691,95 \%$ CI 1.209-2.364, $P=0.002$ ) and sugar consumption (OR: $1.75,95 \%$ CI 1.161-2.639, $P=0.008$ ) were also found to contribute to a higher prevalence of calculus. The GB model (Table 4) revealed that the students who brushed their teeth less than twice a day (1/day: OR: $1.235,95 \% \mathrm{CI}$ $1.028-1.483, P=0.024$; $<1 /$ day: OR: 1.791 , $95 \%$ CI $1.373-$ 2.335, $P<0.001)$ and do not use dental floss (OR: 1.928, 95\% CI 1.373-2.706, $P<0.001)$ generally experienced worse gingival bleeding. Moreover, age, living region, and the belief that gingival bleeding when brushing is normal were also associated with GB. 
Table 1 Statistical significance by demographic variables for dental caries, calculus and gingival bleeding among 12-15-year-old students $(n=3868)$. N (\%)

\begin{tabular}{|c|c|c|c|c|c|c|c|c|c|}
\hline \multirow[t]{2}{*}{ Variables } & \multicolumn{3}{|l|}{ Dental caries } & \multicolumn{3}{|l|}{ Calculus } & \multicolumn{3}{|c|}{ Gingival bleeding } \\
\hline & Absence & Presence & $P$ value & Absence & Presence & $P$ value & Absence & Presence & $P$ value \\
\hline Total & $2326(60.1 \%)$ & 1542 (39.9\%) & & 708 (18.3\%) & $3160(81.7 \%)$ & & $2656(68.7 \%)$ & $1212(31.3 \%)$ & \\
\hline \multicolumn{10}{|l|}{ Age group } \\
\hline 12 years & $589(62.7 \%)^{a}$ & $351(37.3 \%)^{\mathrm{a}}$ & \multirow[t]{4}{*}{0.041} & $225(23.9 \%)^{\mathrm{a}}$ & $715(76.1 \%)^{\mathrm{a}}$ & \multirow[t]{4}{*}{$<0.001$} & $666(70.9 \%)^{a}$ & $274(29.1 \%)^{a}$ & \multirow[t]{4}{*}{0.01} \\
\hline 13 years & $582(59.2 \%)^{a, b}$ & $401(40.8 \%)^{a, b}$ & & $175(17.8 \%)^{\mathrm{b}}$ & $808(82.2 \%)^{b}$ & & $666(67.8 \%)^{a, b}$ & $317(32.2 \%)^{a, b}$ & \\
\hline 14 years & $597(61.9 \%)^{\mathrm{a}}$ & $368(38.1 \%)^{\mathrm{a}}$ & & $178(18.4 \%)^{b}$ & $787(81.6 \%)^{b}$ & & $687(71.2 \%)^{\mathrm{a}}$ & $278(28.8 \%)^{a}$ & \\
\hline 15 years & $558(56.9 \%)^{b}$ & $422(43.1 \%)^{b}$ & & $130(13.3 \%)^{c}$ & $850(86.7 \%)^{c}$ & & $637(65.0 \%)^{b}$ & $343(35.0 \%)^{b}$ & \\
\hline \multicolumn{10}{|l|}{ Gender } \\
\hline Male & $1300(66.9 \%)^{\mathrm{a}}$ & $642(33.1 \%)^{\mathrm{a}}$ & \multirow[t]{2}{*}{$<0.001$} & $281(14.5 \%)^{\mathrm{a}}$ & $1661(85.5 \%)^{\mathrm{a}}$ & \multirow{2}{*}{$<0.001$} & $1313(67.6 \%)$ & $629(32.4 \%)$ & \multirow[t]{2}{*}{0.155} \\
\hline Female & $1026(53.3 \%)^{b}$ & $900(46.7 \%)^{b}$ & & $427(22.2 \%)^{b}$ & $1499(77.8 \%)^{b}$ & & $1343(69.7 \%)$ & $583(30.3 \%)$ & \\
\hline \multicolumn{10}{|l|}{ Urban and rural } \\
\hline Urban & 1145 (59.2\%) & $790(40.8 \%)$ & \multirow[t]{2}{*}{0.222} & $380(19.6 \%)^{\mathrm{a}}$ & $1555(80.4 \%)^{\mathrm{a}}$ & \multirow[t]{2}{*}{0.032} & $1270(65.6 \%)^{a}$ & $665(34.4 \%)^{a}$ & \multirow[t]{2}{*}{$<0.001$} \\
\hline Rural & $1181(61.1 \%)$ & $752(38.9 \%)$ & & $328(17.0 \%)^{b}$ & $1605(83.0 \%)^{b}$ & & $1386(71.7 \%)^{b}$ & $547(28.3 \%)^{b}$ & \\
\hline \multicolumn{10}{|l|}{ Region } \\
\hline Shouguang Weifang & $540(56.4 \%)^{\mathrm{a}}$ & $418(43.6 \%)^{\mathrm{a}}$ & \multirow[t]{4}{*}{$<0.001$} & $187(19.5 \%)^{a}$ & $771(80.5 \%)^{\mathrm{a}}$ & \multirow[t]{4}{*}{0.001} & $665(69.4 \%)^{a}$ & $293(30.6 \%)^{\mathrm{a}}$ & \multirow[t]{4}{*}{$<0.001$} \\
\hline Huancui, Weihai & $550(58.0 \%)^{\mathrm{a}}$ & $399(42.0 \%)^{\mathrm{a}}$ & & $168(17.7 \%)^{\mathrm{a}}$ & $781(82.3 \%)^{\mathrm{a}}$ & & $588(62.0 \%)^{b}$ & $361(38.0 \%)^{b}$ & \\
\hline Hedong, Linyi & $595(60.3 \%)^{a, b}$ & $391(39.7 \%)^{a, b}$ & & $212(21.5 \%)^{b}$ & $774(78.5 \%)^{b}$ & & $682(69.2 \%)^{\mathrm{a}}$ & $304(30.8 \%)^{\mathrm{a}}$ & \\
\hline Pingyi, Linyi & $641(65.7 \%)^{b}$ & $334(34.3 \%)^{b}$ & & $141(14.5 \%)^{c}$ & $834(85.5 \%)^{c}$ & & $721(73.9 \%)^{c}$ & $254(26.1 \%)^{c}$ & \\
\hline \multicolumn{10}{|l|}{ An only child or not? } \\
\hline Yes & $913(62.7 \%)^{\mathrm{a}}$ & $542(37.3 \%)^{\mathrm{a}}$ & \multirow[t]{2}{*}{0.01} & $274(18.8 \%)$ & $1181(81.2 \%)$ & \multirow[t]{2}{*}{0.51} & $997(68.5 \%)$ & $458(31.5 \%)$ & \multirow[t]{2}{*}{0.881} \\
\hline No & $1413(58.6 \%)^{b}$ & $1000(41.4 \%)^{b}$ & & $434(18.0 \%)$ & $1979(82.0 \%)$ & & $1659(68.8 \%)$ & $754(31.2 \%)$ & \\
\hline \multicolumn{10}{|l|}{ Father's education level } \\
\hline Never go to school & $10(62.5 \%)$ & $6(37.5 \%)$ & \multirow[t]{5}{*}{0.286} & $3(18.8 \%)$ & $13(81.3 \%)$ & \multirow[t]{5}{*}{0.712} & $9(56.3 \%)$ & $7(43.8 \%)$ & 0.274 \\
\hline $\begin{array}{l}\text { Elementary or junior high } \\
\text { school }\end{array}$ & $1476(61.3 \%)$ & $932(38.7 \%)$ & & $425(17.6 \%)$ & 1983 (82.4\%) & & $1646(68.4 \%)$ & $762(31.6 \%)$ & \\
\hline High school & $318(56.6 \%)$ & $244(43.4 \%)$ & & $112(19.9 \%)$ & $450(80.1 \%)$ & & $374(66.5 \%)$ & $188(33.5 \%)$ & \\
\hline College or university & 349 (59.9\%) & $234(40.1 \%)$ & & $109(18.7 \%)$ & $474(81.3 \%)$ & & $418(71.7 \%)$ & $165(28.3 \%)$ & \\
\hline No father or do not know & $173(57.9 \%)$ & $126(42.1 \%)$ & & $59(19.7 \%)$ & $240(80.3 \%)$ & & 209 (69.9\%) & $90(30.1 \%)$ & \\
\hline Mother's education level & & & & & & & & & \\
\hline Never go to school & $103(68.7 \%)^{\mathrm{a}}$ & $47(31.3 \%)^{\mathrm{a}}$ & 0.005 & $29(19.3 \%)$ & $121(80.7 \%)$ & 0.519 & $103(68.7 \%)$ & $47(31.3 \%)$ & 0.255 \\
\hline $\begin{array}{l}\text { Elementary or junior high } \\
\text { school }\end{array}$ & $1545(61.2 \%)^{b}$ & $978(38.8 \%)^{b}$ & & $446(17.7 \%)$ & $2077(82.3 \%)$ & & $1728(68.5 \%)$ & $795(31.5 \%)$ & \\
\hline High school & $197(53 \%)^{c}$ & $175(47 \%)^{c}$ & & $74(19.9 \%)$ & $298(80.1 \%)$ & & $247(66.4 \%)$ & $125(33.6 \%)$ & \\
\hline College or university & $290(59.1 \%)^{c}$ & $201(40.9 \%)^{c}$ & & $101(20.6 \%)$ & 390 (79.4\%) & & $357(72.7 \%)$ & $134(27.3 \%)$ & \\
\hline $\begin{array}{l}\text { No mother or do not } \\
\text { know }\end{array}$ & $191(57.5 \%)^{b, c}$ & $141(42.5 \%)^{b, c}$ & & $58(17.5 \%)$ & $274(82.5 \%)$ & & $221(66.6 \%)$ & $111(33.4 \%)$ & \\
\hline
\end{tabular}

a,b,c Differences between the row variables, the same mark represents no difference between the two variables

\section{Discussion}

This study evaluated the sociodemographic, clinical, oral health knowledge, attitudes, and behavioural factors among 12-15-year-old students in Shandong province and analysed the association between non-clinical variables and the DMFT, CI, and GB indices (clinical variables). The results show that the prevalence of caries in Shandong province is similar to the national level $(31.9 \%$ vs $41.9 \%$ ) [3], the detection rate of calculus is higher than it is nationally ( $81.7 \%$ vs $67.3 \%)$, while the gingival bleeding rate is lower than nationally (31.3\% vs $61.0 \%)$ [4]. These inconsistencies may be related to the geographic location of Shandong province, the diet habits and oral health behaviours of adolescents, etc. Therefore, further oral diseases associated factors were explored and analysed in this study.

Dental caries are an age-related disease [20-22], which is relate to the continuous development of oral diseases over time without any intervention [23]. In addition, there is an association between gender and 
Table 2 Multivariable logistic regression model for dental caries ( $n=3868$; method: backward)

\begin{tabular}{|c|c|c|c|}
\hline Variables & OR & $95 \% \mathrm{Cl}$ & $P$ value \\
\hline \multicolumn{4}{|l|}{ Age group } \\
\hline 12 years & 1 & NA & NA \\
\hline 13 years & 1.176 & $0.971-1.425$ & 0.096 \\
\hline 14 years & 1.045 & $0.861-1.268$ & 0.653 \\
\hline 15 years & 1.322 & $1.092-1.601$ & 0.004 \\
\hline \multicolumn{4}{|l|}{ Region } \\
\hline Shouguang, Weifang & 1.397 & $1.140-1.711$ & 0.001 \\
\hline Huancui, Weihai & 1.435 & $1.158-1.779$ & 0.001 \\
\hline Hedong, Linyi & 1.12 & $0.923-1.360$ & 0.252 \\
\hline Pingyi, Linyi & 1 & NA & NA \\
\hline \multicolumn{4}{|l|}{ Gender } \\
\hline Female & 1.69 & $1.471-1.943$ & $<0.001$ \\
\hline Male & 1 & NA & NA \\
\hline \multicolumn{4}{|l|}{ An only child or not? } \\
\hline Yes & 1 & NA & NA \\
\hline No & 1.253 & $1.065-1.474$ & 0.007 \\
\hline \multicolumn{4}{|c|}{ Q12 self-evaluation of oral health condition } \\
\hline Great & 1 & NA & NA \\
\hline Good & 1.415 & $1.0-2.003$ & 0.05 \\
\hline General & 1.518 & $1.080-2.134$ & 0.016 \\
\hline Poor & 2.633 & $1.82-3.896$ & $<0.001$ \\
\hline Severe & 3.346 & $1.783-6.278$ & $<0.001$ \\
\hline \multicolumn{4}{|c|}{ Q15 toothache in the past 12 months } \\
\hline Usually & 2.207 & $1.391-3.501$ & 0.001 \\
\hline Occasionally & 1.482 & $1.264-1.736$ & $<0.001$ \\
\hline Do not remember & 0.995 & $0.795-1.244$ & 0.963 \\
\hline Never & 1 & NA & NA \\
\hline \multicolumn{4}{|l|}{ Q16 visited a dentist } \\
\hline Yes & 1.728 & $1.501-1.990$ & $<0.001$ \\
\hline Never & 1 & NA & NA \\
\hline \multicolumn{4}{|c|}{ Q21f the impact of oral problems on sleeping } \\
\hline Serious impact & 1.538 & $1.080-2.190$ & 0.017 \\
\hline General impact & 0.998 & $0.749-1.330$ & 0.991 \\
\hline Minor impact & 1.193 & $0.980-1.452$ & 0.079 \\
\hline Unclear & 0.756 & $0.527-1.084$ & 0.128 \\
\hline No impact & 1 & NA & NA \\
\hline
\end{tabular}

$O R$ odd rates, $C l$ confidence interval, $N A$ not applicable

caries. Here, a higher frequency of caries is detected in females, which may be related to their preference for dessert (Q9a, over 2 times/day: male: 43.9\%, female: $56.1 \%, P<0.0001$. data not shown), the hormonal fluctuations in puberty and menstruation [24], or even the sex-based diverse plaque microbiome [25]. However, some studies found that males usually have a higher frequency of caries $[26,27]$. In other words, the association between gender and caries is been confirmed, but not fixed. Furthermore, gender is also associated with
Table 3 Multivariate logistic regression model for calculus (method: backward)

\begin{tabular}{|c|c|c|c|}
\hline Variables & OR & $95 \% \mathrm{Cl}$ & $P$ value \\
\hline \multicolumn{4}{|l|}{ Age group } \\
\hline 12 years & 1 & NA & NA \\
\hline 13 years & 1.566 & $1.227-2$ & $<0.001$ \\
\hline 14 years & 1.366 & $1.074-1.736$ & 0.011 \\
\hline 15 years & 2.131 & $1.65-2.753$ & $<0.001$ \\
\hline \multicolumn{4}{|l|}{ Region } \\
\hline Shouguang, Weifang & 1.236 & $0.972-1.573$ & 0.084 \\
\hline Huancui, Weihai & 1.456 & $1.133-1.871$ & 0.003 \\
\hline Pingyi, Linyi & 1.554 & $1.190-2.028$ & 0.001 \\
\hline Hedong, Linyi & 1 & NA & NA \\
\hline \multicolumn{4}{|l|}{ Gender } \\
\hline Male & 1.57 & $1.307-1.886$ & $<0.001$ \\
\hline Female & 1 & NA & NA \\
\hline \multicolumn{4}{|c|}{ Q5 frequency of brushing $(n=3356)$} \\
\hline$\geq 2 /$ day & 1 & NA & NA \\
\hline $1 /$ day & 1.421 & $1.158-1.742$ & 0.001 \\
\hline$<1 /$ day & 1.691 & $1.209-2.364$ & 0.002 \\
\hline \multicolumn{4}{|c|}{ Q9a frequency of having sweets } \\
\hline Seldom or never & 1.75 & $1.161-2.639$ & 0.008 \\
\hline $1-3 /$ month & 1.37 & $0.944-1.988$ & 0.098 \\
\hline 1/week & 1.318 & $0.951-1.827$ & 0.097 \\
\hline 2-6/week & 1.311 & $0.981-1.752$ & 0.067 \\
\hline 1/day & 1.1 & $0.8-1.512$ & 0.557 \\
\hline$\geq 2 /$ day & 1 & NA & NA \\
\hline \multicolumn{4}{|c|}{ Q16 whether visited a dentist } \\
\hline Yes & 1 & NA & NA \\
\hline Never & 1.249 & $1.037-1.504$ & 0.019 \\
\hline
\end{tabular}

OR odd rates, $\mathrm{Cl}$ confidence interval, $N A$ not applicable

the gingival health. Here, boys tend to have more severe gingival health status than girls, as supported by many studies [28-30]. Boy's poor oral hygiene habits (Q4, toothbrushing: yes: male vs female: $45.5 \%$ vs $54.5 \%$; occasionally or never: male vs female: $80.9 \%$ vs $19.1 \%$. $P<0.0001 ; \mathrm{Q} 5$, frequency of brushing: twice daily: male vs female: $38.5 \%$ vs $61.5 \%, P<0.0001$. data not shown) may be contribute to this result [6].

In addition, region is also an associated factor related to caries, calculus and gingival bleeding. Especially adolescents living in Weifang and Weihai are more likely to experience dental caries and gingival bleeding than those living in Linyi. This may be results from the special dietary habits in Linyi area. Residents living in Linyi take a hard and tough pancake as their staple food, which is made from coarse grains. The low adhesion and easy friction properties of this food may hinder the accumulation of dental plaque, thereby reducing the prevalence of dental caries in this area. 
Table 4 Multivariate logistic regression model for gingival bleeding (method: backward)

\begin{tabular}{|c|c|c|c|}
\hline Variables & OR & $95 \% \mathrm{Cl}$ & $P$ value \\
\hline \multicolumn{4}{|l|}{ Age group } \\
\hline 12 years & 1.09 & $0.876-1.356$ & 0.441 \\
\hline 13 years & 1.27 & $1.027-1.571$ & 0.028 \\
\hline 14 years & 1 & NA & NA \\
\hline 15 years & 1.354 & $1.1-1.667$ & 0.004 \\
\hline \multicolumn{4}{|l|}{ Region } \\
\hline Shouguang, Weifang & 1.288 & $1.032-1.608$ & 0.025 \\
\hline Huancui, Weihai & 2.109 & $1.686-2.636$ & $<0.001$ \\
\hline Hedong, Linyi & 1.233 & $0.989-1.537$ & 0.063 \\
\hline Pingyi, Linyi & 1 & NA & NA \\
\hline \multicolumn{4}{|c|}{ Q5 frequency of brushing $(n=3356)$} \\
\hline$\geq 2 /$ day & 1 & NA & NA \\
\hline 1/day & 1.235 & $1.028-1.483$ & 0.024 \\
\hline$<1 /$ day & 1.791 & $1.373-2.335$ & $<0.001$ \\
\hline \multicolumn{4}{|c|}{ Q8 frequency of using dental floss } \\
\hline Never & 1.928 & $1.373-2.706$ & $<0.001$ \\
\hline Occasionally & 1 & NA & NA \\
\hline Weekly use & 0.642 & $0.135-3.061$ & 0.579 \\
\hline Daily use & 1.24 & $0.311-4.954$ & 0.76 \\
\hline \multicolumn{4}{|c|}{ Q19a is gingival bleeding normal when brushing your teeth? } \\
\hline Yes & 1.516 & $1.225-1.875$ & $<0.001$ \\
\hline Do not know & 1.322 & $1.025-1.704$ & 0.031 \\
\hline No & 1 & NA & NA \\
\hline
\end{tabular}

$O R$ odd rates, $C l$ confidence interval, NA not applicable

Unfortunately, these associated factors, including age, gender, and region are all uncontrollable factors, even if there are significant differences. Therefore, stratification is important for the analysis and assessment of the risk factors at different levels. Moreover, an analysis of controllable oral diseases associated variables is more important to provide robust guidance for oral health education content.

The contribution of toothbrushing to remove dental plaque and maintain oral health has been proven [31-33]. However, many of these cross-sectional studies and even longitudinal studies $[15,34,35]$ are consistent with our results, and found that there is no association between toothbrushing and dental caries. We speculate that this result may be related to individual's brushing efficiency, that is, whether the toothbrushing practices get the maximum effect to remove dental plaque [10]. This also explains why girls suffer from dental caries more frequently in this study. Girls prefer desserts, even though they brush their teeth twice a day, they still have a high incidence of dental caries. After all, toothbrushing is already a very common oral health care behaviour in China, but how to ensure and improve the efficiency of individuals toothbrushing is the direction we should strive for now. Currently, an increasing number of prospective intervention studies have confirmed that additional brushing guidance or even just a simple application of plaque disclosing tables can improve oral hygiene [36, 37]. Hence, an assessment of brushing efficiency should be incorporated into future research to estimate the correlation between toothbrushing and dental caries more accurately. In addition, the positive effect of brushing more than twice a day on preventing calculus formation and gingival bleeding were confirmed in our study. Evidence shows that, without considering the efficacy of tooth brushing, correct oral hygiene can help to maintain gingival health $[6,38]$.

Preventative dental visits are highly recommended [39]. However, in China, there seems to be still a long way to go, as dental visits were generally associated with worse caries status [40, 41], and dental visits for treatment is a vital attribution factor. Better calculus status was detected among adolescents who had visited the dentist (Additional file 1: Table S2, Table 3), which may be related to the time-efficiency of calculus removal. Furthermore, those individuals that had experienced a toothache in the past 12 months, and sleeping troubles caused by oral problems were found to have a more severe caries status (Additional file 1: Table S1, Table 2), so they evaluated themselves as having poor oral health. However, $81.7 \%$ of individuals with calculus and $31.3 \%$ with gingival bleeding, did not realize that their oral health was very poor. Furthermore, $14.1 \%$ of adolescents thought that gingival bleeding was normal when brushing teeth, indicating that compared to caries, some characteristics of gingivitis, especially the formation of calculus, are not often taken seriously or even ignored when adolescents selfevaluate oral health status. If adolescents continue to pay little attention to initial periodontal inflammation, more serious periodontal issues will inevitably appear in the future [8]. Therefore, these aspects should be focussed on when conducting oral health education in the future.

The sufficient sample size and the comprehensive collection of various potential associated factor information enabled this study to reliably evaluate the oral health status of adolescents in Shandong province. However, the present study also had some limitations. First, cross-sectional studies are unable to prove causal inference. Second, the correlation between toothbrushing and caries could not be accurately evaluated because toothbrushing efficiency was not assessed. Third, even though the region that the adolescents lived in was an associated factor that correlated with DMFT, $\mathrm{CI}$, and GB, no information on the familial socioeconomic status was recorded. It is known that familial socioeconomic status is closely linked with oral health 
status [42-44]. Due to living standard improvements, a simple urban-rural classification does not truly reflect the correlation between socioeconomic status and oral health. Finally, the odds ratios may overestimate the prevalence ratios especially when prevalence is high and thus caution should be taken in interpreting the results.

\section{Conclusion}

In conclusion, compared to caries, worse gingival condition is more prevalent among adolescents in Shandong and its signs are not taken seriously. Age, gender, region, toothaches, dental visits and sleeping troubles caused by oral problems were found to be associated with dental caries in adolescents. A low-frequency of brushing and sugar consumption were associated with the formation of calculus. A low-frequency of brushing and no flossing were associated with gingival bleeding. Preventative dental visits and oral hygiene training are strongly recommended to improve oral health status.

\section{Abbreviations}

DMFT: Decayed, missing and filled permanent teeth; Cl: Calculus index; GB: Gingival bleeding index; OR: Odd rates; Cl: Confidence interval.

\section{Supplementary Information}

The online version contains supplementary material available at https://doi. org/10.1186/s12903-021-01640-x.

Additional file 1: Table S1. Bivariate analysis of potential variables related to the prevalence of dental caries. N (\%). Table S2. Bivariate analysis of potential variables related to the prevalence of calculus. N (\%). Table S3. Bivariate analysis of potential variables related to the prevalence of gingival bleeding. N (\%). Table S4. Binary logistic regression analysis for dental caries (unadjusted). Table S5. Binary logistic regression analysis for calculus (unadjusted). Table $\mathbf{S 6}$. Binary logistic regression analysis for gingival bleeding (unadjusted)

\section{Acknowledgements}

Our warmest thanks to the Chinese Stomatological Association for providing the raw survey data. Thank you also for the cooperation and assistance of the various primary and high schools.

\section{Authors' contributions}

ZFW conceptualized and designed the study, ZFW and JL reviewed and revised the manuscript. $M Z$ organized data, carried out the statistical analysis, drafted and revised the manuscript. TTZ and WSS collected, input and organized data. PPL instructed the methods and strategies of statistical analysis. All authors reviewed the manuscript. All authors read and approved the final manuscript.

\section{Funding}

All phases of this study were supported by the Chinese Stomatological Association and School \& Hospital of Stomatology, Shandong University. The design of this study and collection, analysis, and interpretation of data and the manuscript writing are funded by the Key Technology Research and Development Program of Shandong Province (Grant Numbers: 2019 GSF108278 and 2019GSF108184), National Natural Science Foundation of China (Grant
Number: 81671025), and the Department of Science and Technology of Shandong Province (Grant Number: ZR2018ZB0105).

\section{Availability of data and materials}

The datasets used and analyzed during the current study are available from the corresponding author on reasonable request.

\section{Declarations}

Ethics approval and consent to participate

Ethical approval was obtained from the Ethics Committee of the Chinese Stomatological Association (No. 2014-003). Written informed consent was obtained from adolescent's legal guardians.

\section{Consent for publication}

Not applicable.

\section{Competing interests}

The authors declare that they have no competing interests.

Received: 12 January 2021 Accepted: 17 May 2021

Published online: 05 June 2021

\section{References}

1. Peres MA, Macpherson LMD, Weyant RJ, Daly B, Venturelli R, Mathur MR, Listl S, Celeste RK, Guarnizo-Herreño CC, Kearns C, Benzian H, Allison P, Watt RG. Oral diseases: a global public health challenge. Lancet. 2019;394(10194):249-60.

2. Kassebaum NJ, Smith AGC, Bernabé E, Fleming TD, Reynolds AE, Vos T, Murray CJL, Marcenes W, GBD 2015 Oral Health Collaborators. Global, regional, and national incidence, prevalence, and years lived with disability for 328 diseases and injuries for 195 countries, 1990-2016: a systematic analysis for the Global Burden of Disease Study 2016. Lancet. 2017;390(10100):1211-59.

3. Quan JK, Wang XZ, Sun XY, Yuan C, Liu XN, Wang X, Feng XP, Tai BJ, Hu Y, Lin HC, Wang B, Si Y, Wang CX, Wang WJ, Rong WS, Zheng SG. Permanent teeth caries status of 12- to 15-year-olds in China: finding from the 4th national oral health survey. Chin J Dent Res. 2018;21(3):181-93.

4. Chen X, Ye W, Zhan JY, Wang X, Tai BJ, Hu Y, Lin HC, Wang B, Si Y, Wang CX, Zheng SG, Liu XN, Rong WS, Wang WJ, Feng XP. Periodontal status of Chinese adolescents: findings from the 4 th national oral health survey. Chin J Dent Res. 2018;21(3):195-203.

5. Al-Hussyeen AJ. Factors affecting utilization of dental health services and satisfaction among adolescent females in Riyadh City. Saudi Dent J. 2010;22(1):19-25.

6. Woelber JP, Bienas H, Fabry G, Silbernagel W, Giesler M, Tennert C, Stampf S, Ratka-Krüger P, Hellwig E. Oral hygiene-related self-efficacy as a predictor of oral hygiene behaviour: a prospective cohort study. J Clin Periodontol. 2015:42(2):142-9.

7. Cumerlato CBDF, Demarco FF, Barros AJD, Peres MA, Peres KG, Morales Cascaes A, de Camargo MBJ, da Silva Dos Santos I, Matijasevich A, Corrêa $M B$. Reasons for direct restoration failure from childhood to adolescence: a birth cohort study. J Dent. 2019;89:103183.

8. Drummond BK, Brosnan MG, Leichter JW. Management of periodontal health in children: pediatric dentistry and periodontology interface. Periodontol. 2017;74(1):158-67.

9. Thornton-Evans $G$, Junger ML, Lin M, Wei L, Espinoza L, Beltran-Aguilar E. Use of toothpaste and toothbrushing patterns among children and adolescents_United States, 2013-2016. Morb Mortal Wkly Rep. 2019;68(4):87-90.

10. Jepsen S, Blanco J, Buchalla W, Carvalho JC, Dietrich T, Dörfer C, Eaton KA, Figuero E, Frencken JE, Graziani F, Higham SM, Kocher T, Maltz M, Ortiz-Vigon A, Schmoeckel J, Sculean A, Tenuta LM, van der Veen MH, Machiulskiene $\mathrm{V}$. Prevention and control of dental caries and periodontal diseases at individual and population level: consensus report of group 3 of joint EFP/ORCA workshop on the boundaries between caries and periodontal diseases. J Clin Periodontol. 2017. https://doi.org/10.1111/jcpe. 12687:S85-593. 
11. Xiang B, Wong HM, Perfecto AP, McGrath CPJ. The association of socioeconomic status, dental anxiety, and behavioral and clinical variables with adolescents' oral health-related quality of life. Qual Life Res. 2020. https://doi.org/10.1007/s11136-020-02504-7.

12. Eid SA, Khattab NMA, Elheeny AAH. Untreated dental caries prevalence and impact on the quality of life among 11 to14-year-old Egyptian schoolchildren: a cross-sectional study. BMC Oral Health. 2020;20(1):83.

13. Ferrazzano GF, Salerno C, Sangianantoni G, Caruso S, Ingenito A, Cantile T. The effect of dental treatment under general anesthesia on quality of life and growth and blood chemistry parameters in uncooperative pediatric patients with compromised oral health: a pilot study. Int J Environ Res Public Health. 2020;17(12):4407.

14. Kyaw Myint ZC, Zaitsu T, Oshiro A, Ueno M, Soe KK, Kawaguchi Y. Risk indicators of dental caries and gingivitis among 10-11-year-old students in Yangon, Myanmar. Int Dent J. 2020;70(3):167-75.

15. Du A, Zhang H, Chen C, Zhang F, Liu X, Zhang Z, Wang R. Oral health of 12-year-old children in Jilin province, China: a population-based epidemiological survey. Medicine. 2019;98(51):e18463.

16. Skeie MS, Klock KS. Dental caries prevention strategies among children and adolescents with immigrant-or low socioeconomic backgroundsdo they work? A systematic review. BMC Oral Health. 2018;18(1):20.

17. Lu HX, Tao DY, Lo ECM, Li R, Wang X, Tai BJ, Hu Y, Lin HC, Wang B, Si Y, Wang CX, Zheng SG, Liu XN, Rong WS, Wang WJ, Feng XP. The 4th national oral health survey in the mainland of China: background and methodology. Chin J Dent Res. 2018;21(3):161-5.

18. Yuan C, Wang XZ, Sun XY, Wang X, Feng XP, Tai BJ, Hu Y, Lin HC, Wang B, Si Y, Wang CX, Rong WS, Wang WJ, Zheng SG, Liu XN. Oral health status of 12 -year-olds from regions with and without coverage of the national oral health comprehensive intervention program for children in China. Chin J Dent Res. 2018;21(4):299-306.

19. World Health Organization (WHO). Oral health surveys: basic methods. 5th ed. Gevena: World Health Organization; 2013.

20. Montanha-Andrade K, Maia W, Pimentel ACP, Arsati YBOL, Santos JND, Cury PR. Dental health status and its indicators in adult Brazilian Indians without exposition to drinking water fluoridation: a cross-sectional study. Environ Sci Pollut Res Int. 2019;26(33):34440-7.

21. lida $H$, Auinger P, Billings RJ, Weitzman M. Association between infant breastfeeding and early childhood caries in the United States. Pediatrics. 2007;120(4):e944-52.

22. Bernabé $E$, Sheiham A. Age, period and cohort trends in caries of permanent teeth in four developed countries. Am J Public Health. 2014:104(7):e115-21.

23. Pitts NB, Zero DT, Marsh PD, Ekstrand K, Weintraub JA, Ramos-Gomez F, Tagami J, Twetman S, Tsakos G, Ismail A. Dental caries. Nat Rev Dis Prim. 2017;3(1):17030

24. Lukacs JR, Largaespada LL. Explaining sex differences in dental caries prevalence: saliva, hormones, and "life-history" etiologies. Am J Hum Biol. 2006;18(4):540-55.

25. de Jesus VC, Shikder R, Oryniak D, Mann K, Alamri A, Mittermuller B, Duan K, Hu P, Schroth RJ, Chelikani P. Sex-based diverse plaque microbiota in children with severe caries. J Dent Res. 2020;99(6):703-12

26. Mamai-Homata E, Koletsi-Kounari H, Margaritis V. Gender differences in oral health status and behavior of Greek dental students: a metaanalysis of 1981, 2000, and 2010 data. J Int Soc Prev Community Dent. 2016:6(1):60-8.

27. Wang K, Pang L, Tao Y, Li X, Zhang J, Cui T, Zeng B, Lin H. Association of genetic and environmental factors with dental caries among adolescents in south China: a cross-sectional study. Eur J Paediatr Dent. 2020;21(2):129-36.

28. Pedersen AML, Darwish M, Nicholson J, Edwards MI, Gupta AK, Belstrøm D. Gingival health status in individuals using different types of toothpaste. J Dent. 2019. https://doi.org/10.1016/j.jdent.2018.08.008:S13-S8.
29. Christensen LB, Petersen PE, Steding-Jessen M. Consumption of dental services among adults in Denmark 1994-2003. Eur J Oral Sci. 2007:115(3):174-9.

30. Shiau HJ, Reynolds MA. Sex differences in destructive periodontal disease: a systematic review. J Periodontol. 2010;81(10):1379-89.

31. Scherp HW. Dental caries: prospects for prevention. Science. 1971:173(4003):1199-205.

32. Worthington HV, MacDonald L, Poklepovic Pericic T, Sambunjak D, Johnson TM, Imai P, Clarkson JE. Home use of interdental cleaning devices, in addition to toothbrushing, for preventing and controlling periodontal diseases and dental caries. Cochrane Database Syst Rev. 2019:4:CD012018.

33. Walsh T, Worthington HV, Glenny AM, Marinho VC, Jeroncic A. Fluoride toothpastes of different concentrations for preventing dental caries. Cochrane Database Syst Rev. 2019;3:CD007868.

34. Ju X, Do L, Ha D, Jamieson L. Association of modifiable risk factors with dental caries among indigenous and nonindigenous children in Australia. JAMA Netw Open. 2019:2(5):e193466.

35. Suzuki S, Onose Y, Yoshino K, Takayanagi A, Kamijo H, Sugihara N. Factors associated with development of root caries in dentition without root caries experience in a 2-year cohort study in Japan. J Dent. 2020;95:103304.

36. Gray-Burrows KA, Day PF, Marshman Z, Aliakbari E, Prady SL, McEachan RR. Using intervention mapping to develop a home-based parentalsupervised toothbrushing intervention for young children. Implement Sci. 2016;11:61.

37. Shiotsu-Ogura Y, Yoshida A, Kan P, Sasaki H, Toyama T, Izukuri K, Hamada $\mathrm{N}$, Yoshino F. Antimicrobial photodynamic therapy using a plaque disclosing solution on Streptococcus mutans. Photodiagnosis Photodyn Therapy. 2019;26:252-7.

38. Mizutani S, Ekuni D, Furuta M, Tomofuji T, Irie K, Azuma T, Kojima A, Nagase J, Iwasaki Y, Morita M. Effects of self-efficacy on oral health behaviours and gingival health in university students aged 18- or 19-years-old. J Clin Periodontol. 2012;39(9):844-9.

39. Guarnizo-Herreño CC, Wehby GL. Dentist supply and children's oral health in the United States. Am J Public Health. 2014;104(10):e51-7.

40. Obregón-Rodríguez N, Fernández-Riveiro P, Piñeiro-Lamas M, SmythChamosa E, Montes-Martínez A, Suárez-Cunqueiro MM. Prevalence and caries-related risk factors in schoolchildren of 12- and 15-year-old: a cross-sectional study. BMC Oral Health. 2019;19(1):120.

41. Zhang M, Zhang X, Zhang Y, Li Y, Shao C, Xiong S, Lan J, Wang Z. Assessment of risk factors for early childhood caries at different ages in Shandong, China and reflections on oral health education: a cross-sectional study. BMC Oral Health. 2020;20(1):139.

42. Petersen PE, Bourgeois D, Ogawa H, Estupinan-Day S, Ndiaye C. The global burden of oral diseases and risks to oral health. Bull World Health Organ. 2005;83(9):661-9.

43. Hosseinpoor AR, Itani L, Petersen PE. Socio-economic inequality in oral healthcare coverage: results from the World Health Survey. J Dent Res. 2012;91(3):275-81.

44. Östberg AL, Petzold M. A longitudinal study of the impact of change in socioeconomic status on dental caries in the permanent dentition of Swedish children and adolescents. Community Dent Oral Epidemiol. 2020. https://doi.org/10.1111/cdoe.12529.

\section{Publisher's Note}

Springer Nature remains neutral with regard to jurisdictional claims in published maps and institutional affiliations. 